\title{
Stancetaking in spoken ELF discourse in academic settings: interpersonal functions of I don't know as a face-maintaining strategy
}

\author{
Hatime Çiftçi a * (1), Erdem Akbaş b \\ ${ }^{a}$ MEF University, Faculty of Education, Ayazağa Cad. No.4, Maslak - Sarıyer - İstanbul, 34396, Turkey \\ ${ }^{b}$ Erciyes University, Ziya Eren Eğitim Fakültesi, Kayseri, 38039, Turkey
}

\begin{tabular}{l|l|l} 
Received 15 December 2020 & Received in revised form 25 March 2021 & Accepted 5 April 2021
\end{tabular}

\begin{abstract}
APA Citation:
Çiftçi, H. \& Akbaş, E. (2021). Stancetaking in spoken ELF discourse in academic settings: interpersonal functions of $I$ don't know as a face-maintaining strategy. Eurasian Journal of Applied Linguistics, 7(1), 484-502.
\end{abstract}

Doi: $10.32601 /$ ejal.911499

\begin{abstract}
Our study examines interpersonal functions enacted through a stance marker in spoken ELF academic discourse. We specifically focus on investigating the functions of $I$ don't know in an academic speech event by embracing an interpersonal pragmatics and sociolinguistics perspective to figure out how it contributes to the act of stancetaking as an intersubjective activity. We have examined 14 interactions of doctoral defense discussions from the ELFA corpus. Our detailed discourse analysis of these doctoral defense discussions has revealed five distinctive interpersonal functions of the stance marker $I$ don't know allowing speakers to construct their stance and adopt a face-maintaining strategy in the ongoing spoken discourse: prefacing a suggestion, seeking acceptance, hedging/mitigating, checking agreement, and expressing uncertainty. Considering the highly-context dependent and context-regenerated functions of I don't know, our study attempts to delve into the relational and interpersonal aspect of communication, and thus contributes to research in this strand by disclosing the interpersonal functions of stancetaking as an intersubjective activity with a particular focus on ELF academic discourse.

(C) 2021 EJAL \& the Authors. Published by Eurasian Journal of Applied Linguistics (EJAL). This is an open-access article distributed under the terms and conditions of the Creative Commons Attribution license (CC BY-NC-ND) (http://creativecommons.org/licenses/by-nc-nd/4.0/).
\end{abstract}

Keywords: Stancetaking; spoken ELF academic discourse; intersubjectivity; interpersonal pragmatics; doctoral defense discussions

\section{Introduction}

Stancetaking in discourse is one of the most frequent social acts performed by interlocutors and can be attributed to linguistic expressions in communication used to convey their personal evaluations or assessments, positioning, opinions and feelings towards what they are saying (Biber \& Finegan, 1988; Conrad \& Biber, 2000). Given that research on functional language has become salient in understanding how

\footnotetext{
* Corresponding author:

E-mail address: ciftcih@mef.edu.tr

http://dx.doi.org/10.32601/ejal.911499
} 
interlocutors interact and communicate in a variety of genres and/or discourses, we come to obtain relatively new insights into stancetaking practices and what interlocutors do with language in such natural discourses for their interactional, communicative, and interpersonal purposes and meaning. A wide range of empirical work on stance in the last two decades have demonstrated that stance in discourse plays an important role in understanding the social and pragmatic aspects of language use in actual interactions and in its own context (Çiftçi \& Vásquez, 2020; Englebretson, 2007; Hunston \& Thompson, 2000; Kärkkäinen, 2007). Our study explores interpersonal functions of stancetaking acts in English as a lingua franca (ELF) discourse in academic settings. Adopting an interdisciplinary approach in understanding stance in ELF discourse, we broadly draw on interpersonal and sociolinguistic perspectives in our analysis of stance in real spoken academic interactions (Jaffe, 2009; O'Driscoll, 2013). Relying on one of the highly frequent stance markers by the native speakers of English (Baumgarten \& House, 2010), we operationalize the act of stancetaking in ELF discourse in academic settings through the use of I don't know in this study.

\section{Literature Review}

\subsection{The notion of stancetaking}

Stance, as clearly defined by Biber (2004), is seen as the expression produced to convey one's personal viewpoints with respect to the information proposed. Concerning the nature of stance, Precht (2003) suggests that the notion needs to be evaluated with the social and cultural contexts as the expression of attitude, emotion, certainty and doubt could vary depending on the very specific linguistic repertoire of the speakers formed by culture and custom. As an example, the corpus analysis by Precht (2003) of daily conversations (totaling almost 1 million words) in American and British English reveals that people largely rely on a smaller set of stance markers (just above 10\%) out of more than 1,400 stance expressions while expressing evaluative language. This indicates that the verbal expression of stance is bound to the choice of the speaker whether it is epistemic or affective stance. Biber and Finegan (1989) clarify the distinction between epistemic and affective stance by accepting the former referring to the attitudes of the speakers towards knowledge and the latter referring to emotional attitudes of the speakers towards their linguistic propositions.

The notion of stance is regarded as one of the open-to-question terms (see Englebretson, 2007; Li, Lei, \& Cheng, 2020). The main reason for the complicated nature of stance could be related to what needs to be done more than identifying particular forms associated with stance (i.e. adverbials) since the explication of the same forms with the investigation of the discourse they are attached to may reveal several types of meaning. With the help of formulating and indexing their stance in a discourse, the interlocutors appear to create their social identities in line with their social actions. In other words, during an interaction, what the interlocutors index 
through their stances could implicitly or explicitly "invoke a constellation of associated social identities" (Jaffe, 2009, p.8).

Expressing stance in an academic context is of great importance since the participants attempt to open up a space for constructing their identity and negotiating with their interlocutors in the act of an exchange. Recent work on stancetaking (see Du Bois, 2007; Haddington, 2005, 2007) has labelled the way how an interlocutor constructs and expresses their stance as "an intersubjective activity" (Haddington, 2007, p.283). Similarly, we understand stance as (inter)subjective (House, 2013) and socially situated within the context it is used as the interlocutors express their own personal evaluation, judgement, and positioning in the ongoing interaction through the use of certain linguistic choices, which mutually influence each other's orientation and (dis)alignment in the discourse. As Jaffe (2009) argues, speakers convey their meanings by projecting their stances which could represent socially and culturally grounded indexicalities. Following this line of conceptualization, it is noteworthy to draw attention to the joint construction of stance throughout an interaction between interlocutors since a speaker negotiates dialogically with the other(s) and positions himself towards other subjects or a particular utterance in the social interaction, which is then followed and evaluated by other co-participants in the interaction. This could also be explained by what Kärkkäinen (2006) labelled as interaction preceded by "intersubjective understanding of the ongoing conversation" (p.704).

The identification of stance and stance markers, as highlighted by Hunston (2007), seems to be a rather complicated process for researchers simply because it is necessary to decipher highly context-dependent forms linked to stance and explore a particular discourse to interpret how the meaning equipped with the stance features is conveyed. Additionally, Silver (2003) argues that the linguistic elements contributing to conveying stance categorized by descriptive models may not be directly "comparable and compatible" (p. 360) in discrete discourses. Such arguments simply call for exploration of such evaluative elements and their functions in their own social contexts and particular genres. Thus, as mentioned earlier, the aim of this paper is to investigate stancetaking act through $I$ don't know in an academic speech event, that is doctoral dissertation defense discussions at university contexts, with a sociolinguistic perspective in order to find out interpersonal functions of that particular stance expression through "narrower and deeper" analysis (Swales, 1990, p.3). Regarding the form of academic discourse in this study, we understand this certain speech event in ELF discourse as a type of institutional discourse with its social dynamics and relevant sociolinguistic factors in the sense that "participants' institutional or professional identities are somehow made relevant to the work activities in which they are engaged" (Drew \& Heritage, 1992, p.3-4). That is, in doctoral dissertation defense discussions as a form of academic discourse at universities, the social roles and interactional goals of the participants and power relations among themselves are known to each other, allowing them to organize their exchanges regarding these goals, roles/identities as well as their own understandings of how to negotiate their 
meaning, self-presentation and thus stancetaking as well as their communicative expectations.

\subsection{Stancetaking and interpersonal pragmatics}

The nature of human communication while conveying information appears to be highly subjective as the interlocutors keep signaling their evaluative judgements on their utterances in one way or another. Since mid/late 1990s (Li et al., 2020), the role of such evaluative judgements and related domains (i.e., evaluation, appraisal and stance) in human communication has received considerable attention from researchers into understanding how the spoken/written communication is shaped by the evaluative dimensions of language in a specific discourse. However, there does not seem to be a common ground as to labelling the evaluative features of language; and therefore, definitions, terminology and categorizations do vary from one context to another (see evaluation by Thompson \& Hunston, 2000; appraisal by Martin, 2000; and stance by Conrad \& Biber, 2000). Li et al. (2020) clearly stress that "there is yet no agreed-upon conception of these terms among researchers" (p.33). This already indicates that the investigation of resources and features qualifying evaluation in a natural discourse requires researchers to designate the theoretical background with which they could operationalize the phenomenon in their own work.

With this in mind, we will refer to the notion of stance to construe a social interaction of an interlocutor to mark his/her interpersonal act as achieving a communicative and dialogic act (Bakhtin, 1981; Du Bois, 2000, 2007). In other words, on top of the propositional content the participant attempts to convey, there are some other meanings attached to the propositional content to reflect the (inter)subjectivity ranging from personal feelings and assessments to judgements. Therefore, we are principally concerned with the dialogic co-action of the participants employing $I$ don't know as an epistemic stance marker to signal pragmatic meanings and functions. Adopting the unified framework of the stance triangle by Du Bois (2007), we shall attempt to operationalize stance in our research context by the three key entities in the act of stance, i.e. Subject 1 (Examiner/PhD Student), Subject 2 (Examiner/PhD Student) and Object. That is, the evaluation from one of the subjects towards the shared object corresponds to what the subject specifies precisely about the object by positioning himself/herself towards the object. The alignment aspect of stancetaking could stem from one of the subjects and be oriented towards the other. The following example from ELFA Corpus is likely to clarify analytic perspective of the concept of stance. The examiner and the $\mathrm{PhD}$ student discuss the impact of anaesthesia (it) in the release of taurine.

$<$ S3> (Examiner): i don't know whether it it should now directly affect the the release

$<$ S2> (PhD Student): yes it shouldn't

(ELFA, 2008, from UDEFD130) 
$<$ S3> as the Subject 1 explicitly evaluates and thereby positions himself towards the shared stance object anaesthesia, in which I don't know serves as the stance marker revealing "the indication of the degree of commitment towards truthfulness" (Biber \& Finegan, 1988, p. 2). What $<\mathrm{S} 2>$ as the Subject 2 uttered in her turn represents evaluation of the stance of $<\mathrm{S} 3>$ towards the shared object, positioning herself towards the proposition and then the alignment occurs through it shouldn't. To recap, during the interaction between the examiner/opponent and the research student, "they index stance in terms of the way they form utterances with regard to each other and to any other object in the world" (Vickers, Deckert, \& Goble, 2014, p.3).

Stancetaking, as discussed by Kärkkäinen (2006), appears to emerge from what is shared between the interlocutors in a particular context, pointing to a "larger cultural and ideological dimension" (p.702), allowing us to consider it a more intersubjective component of language in action because the construct of stance is meaningful when interaction occurs between co-participants of the discourse. In line with this, Du Bois (2000) suggests that the construction and modification of stance can be achieved with the co-existence of a dialogic partner in interaction. This leads us to the interpersonal language use and communication by participants of a micro-social context (i.e. a mathematics classroom, see de Abreu, 2000) embodying interaction. Arundale (2013) views micro-social contexts as discourses where small groups of people construe their social interaction less intimate compared to relational contexts in which the coparticipants build their personal relationship (i.e. close friends). To be able to understand the nature of language and how it works in relational or micro-social contexts, we need to use a more interpersonal communication lens, intercultural pragmatics, revealing "the dynamics of relationships between people and how those relationships are reflected in the language choices that they make" (Locher \& Graham, 2010, p.2.)

In our study, we see a tangible and interwoven connection between stancetaking in discourse and interpersonal pragmatics, and align ourselves to abovementioned elucidations. We embrace an understanding of stancetaking not just expression of evaluations, judgments, positioning, and (dis)alignment at epistemic and/or affective scale but enactment or instantiations of language that is also contributing to the relational or interpersonal aspect of communication (Locher \& Graham, 2010; O'Driscoll, 2013). In our juxtaposition of stancetaking and interpersonal pragmatics, we place a great importance on the notion of face defined as "the positive social value a person effectively claims for himself by the line others assume he has taken during a particular contact" and "an image of self delineated in terms of approved social attributes" by Goffman (1967, p.5). Thus, we see an overlap between the emphasis on self-image and self-representation as a jointly constructed social attribution in every interaction in Goffman's conceptualization of face and stancetaking in discourse as an intersubjective social act as both are context-bounded and relate to the expectations from interlocutors in the discourse. As argued by Locher and Watts (2005), participants are involved in the negotiation of face in any interpersonal interaction and face is an important aspect of relational work, or facework, as interlocutors 
address each other's face while also negotiating their relationships, identities, and meaning. Framing our understanding of stancetaking enacted through I don't know in our study from interpersonal pragmatics approach, we argue that stancetaking also contributes to such relational work that is situated in the social context of interpersonal interaction as a face-maintaining strategy in each interaction rather than simply its prototypical pragmatic function of lack of knowledge (Baumgarten \& House, 2010).

\subsection{Stancetaking in spoken ELF discourse in academic settings}

From a structural perspective, the act of stancetaking by the interlocutor can be signaled through grammatical and lexical constructions. Baumgarten and House (2010) suggested four means of how interlocutors could express their stance towards the propositional content being exchanged. These include (1) complement clauses as in I believe that; (2) adverbial clause constructions uttered at the end of a sentence (i.e., I think, as far as I know, I guess); (3) constructions with lexical verbs as in I disagree on this; (4) adjectives carrying a meaning of evaluation towards an entity. With an explicit reference to themselves as speakers, the use of $I+$ verbs denoting any cognitive process by the speaker about a subject can be regarded as one of the prototypes in expressing subjective meaning and taking stance. In their study, the functional analysis of $I$ think and $I$ don't know collocational units as a means of conveying stance, Baumgarten and House (2010) revealed that these constructions have varied functions in L1 and ELF discourses. Agreeing on the view that "participants in ELF interaction operate on a much smaller common ground of mutually expectable communicative behavior" (Baumgarten \& House, 2010, p.1185), the present study specifically examines the interpersonal functions of I don't know as a stancetaking marker and face-maintaining strategy and also discusses how these functions contribute to ELF communication in the academic contexts with its dynamic nature in a spoken genre.

Based on their bibliometric study, Li et al. (2020) evidenced that research on stancetaking in academic discourse between 2000-2015 has been one of the mostly explored topics. Nevertheless, it should be kept in mind that the identification of expressions qualifying speaker's stance-taking can be highly dependent on the context of research. Therefore, it is not a case that one candidate item used by a speaker to express his/her stance in one context may still function in the same way in another context. As an example, Baumgarten and House (2010) showed that the use of I think by ELF speakers conveys their stances with various functions ranging from giving explanations and sharing personal experience to expressing contrasting views, which are considered to be exclusive in ELF discourse compared to L1 interaction in English. However, such discourse phenomena in ELF academic discourse interactions have received relatively little attention to understand how different varieties of L2 Englishes in interaction result in different patterns of stance-taking. 
With the power and outcome of English spreading across the world as a "non-local lingua franca, the means of communicating between people from anywhere in the world" (Mauranen, 2018, p.8), there has been an increase in the number of academic contexts adopting English as the medium of communication for various purposes (i.e., medium of publication, conferencing, degree programs, so and so forth) especially in the non-English-speaking countries. Following the argument by Mauranen (2018), we believe that the ELF interaction embodies a range of linguistic elements unique to different similects, which are the similarities as a consequence of contacts of a particular L1 with English. Therefore, during a spoken academic ELF interaction, people with different backgrounds essentially need to adopt mechanisms (even at the time of speaking) to deal with a variety of high intellectual activities and content to interact with their interlocutors. Baumgarten and House (2010) argue that stancetaking is one of the domains in which there would be some variations due to the number of different L2 Englishes in the academic discourse community that the interaction takes place. Metsä-Ketelä (2006) has found that the contextualized investigation of more or less as an expression to convey vagueness in the discourse appears to be a unique strategy used by ELF speakers in spoken academic English with the function of 'minimizing' which completely deviated from L1 use. However, as is suggested by Baird, Baker and Kitazawa (2014), it is of great importance to explore how academic communication/culture is built through ELF without the lens of native speaker ideology. It is simply because "international academic culture is a global subculture which is a cultural hybrid, and its English is the language of an interculture" (Mauranen, 2006, p.150). In line with this, zooming in on language practices in an academic ELF setting is likely to allow us to decode the complicated nature of language and meaning-making operated by language users with different similects who also share non-nativeness (Hülmbauer, 2009).

\section{Method}

In this study, we embrace a discourse analytic approach (Gee, 2011) to the analysis of a set of ELF corpus data involving 14 doctoral dissertation defense discussions between a research student and senior academic staff. We acknowledge that our work is interpretative as language itself is a means of such interpretations. Our discourse analysis in this study is also informed by our multidimensional theoretical framework as it draws on various approaches. That is, we understand stancetaking, for instance, as an intersubjective activity where interlocutors express their evaluation, judgment, and positioning through their linguistic choices (Du Bois, 2007; Haddington, 2007; House, 2013). It is also a dialogic act as it is jointly constructed by the interlocutors in the ongoing interaction (Jaffe, 2009; Kärkkäinen, 2006). Thus, understanding stancetaking requires attention to the specific utterance itself. It also necessitates to explore how stancetaking is initiated, to what/whom it is addressed, and how it is responded, and the speech event where it is being performed. Additionally, regarding its intersubjectivity, we understand stancetaking as a social act and thus achieving certain interpersonal functions among the interlocutors. Such an understanding or 
interpretation leads us to a juxtaposition of stancetaking and the concept of face (Goffman, 1967) and examining how this intersection also relates the interpersonal functions in the ELF academic discourse. With these in mind, our interpretations are realized through a detailed analysis of focal linguistic feature within its context and in relation to co-occurring language choices and social roles in the dissertation discussions.

Our data comes from English as a Lingua Franca in Academic Settings (ELFA) corpus of one million transcribed spoken academic ELF communication (ELFA, 2008) in the context of the University of Tampere, the University of Helsinki, Tampere University of Technology, and Helsinki University of Technology. Many speech events ranging from monologic (eg., lectures and presentations) to dyadic or polylogic (e.g., seminars, dissertation defenses, conference discussions) interactions constitute the ELFA corpus from wide spectrum of academic domains, such as social sciences, technology, humanities, natural sciences, medicine, behavioral sciences, and economics and administration. The entire corpus involves around 650 speakers of 51 different first languages.

In this study, we examined a total of 64 instances of epistemic stance marker $I$ don't know in 14 doctoral dissertation defense discussions. First, we used the concordance tool AntConc 3.5.8 (Anthony, 2019) to identify each and every instance of I don't know in our dataset. Then, we zoomed into each concordance hit to understand the functions of I don't know as an epistemic stance marker and how this relates to the interpersonal goals of interlocutors in an academic setting. In 64 instances, we found both interactional (e.g., conversation filler and expressing lack of knowledge) and interpersonal functions of the epistemic marker I don't know and focused on the latter for the purpose of this study. By implementing a discourse analysis approach, we focused on certain representative segments of interactions involving $I$ don't know as a stance marker, which allowed us to decide on five major interpersonal functions of epistemic stance through $I$ don't know as a face-maintaining strategy in doctoral dissertation defense discussion in ELFA corpus. While identifying the interpersonal functions, we considered the social role of interlocutors, surrounding context of the focal linguistic element I don't know, and interpersonal goals of the interlocutors. In doctoral dissertation defense discussions, even though the social roles and of the interlocutors and their goals are known to each other (e.g., being a research student and senior academic staff), it may not be easy to employ certain social acts, such as expressing a suggestion, directing and answering a question, presenting a criticism or an argument. Therefore, our major concern in the identification process was whether the utterance involving $I$ don't know addresses the face needs and/or wants of any parties and whether it is simultaneously conveying an act of stancetaking.

\section{Analysis}

As is suggested by Mauranen (2006), since English has become the common language for international communication in academic settings, research in this 
strand should particularly focus on ELF discourse in such contexts. In this section, we present five interpersonal functions of stancetaking operationalized through the use of epistemic stance marker I don't know in ELF doctoral dissertation discussions. These include prefacing a suggestion, seeking acceptance, hedging or mitigating, checking agreement, and expressing uncertainty. In doing so, we aim to indicate how these functions contribute to the relational aspect and interpersonal goals in the ongoing interaction as they also serve as face-maintaining strategies.

\subsection{Prefacing a suggestion}

The following excerpt comes from a doctoral dissertation defense discussion following the presentation on parallel corpora of literary texts in the academic domain of humanities. A total of 108-minute-interaction involves three male interlocutors who are native speakers of Russian, Finnish, and Swedish. $<\mathrm{S} 1>$ is a junior staff member and defends his dissertation on how parallel corpora, collections of original texts in one language and translations of these texts into another language, can be used in corpus-based research. $<\mathrm{S} 2>$ and $<\mathrm{S} 3>$ are senior staff members who comment and ask questions throughout the discussion.

\section{Excerpt 1}

$1<$ S3> okay . mhm okay, right so let's go on, now i turn to another $<$ S1 $>$ mhm $</$ S1 $>$

2 topic er you say or it is said that you say in this dissertation actually that it's hard

3 to use internal effects to classification parameters $<\mathrm{S} 1>\mathrm{mhm}</ \mathrm{S} 1>$ in your

4 database because er well and and you er you give basically two reasons that the

5 corpus consists of full length literary works $<\mathrm{S} 1>\mathrm{mhm}</ \mathrm{S} 1>$ that they in

6 themselves $<\mathrm{S} 1>\mathrm{mhm}</ \mathrm{S} 1>$ have many sub-parts or $\mathrm{s}$ - $<\mathrm{S} 1>\mathrm{mhm}</ \mathrm{S} 1>$ segments

7 that could be classified differently you you get some amount of dialogue for

8 instance in er in er in er something that is otherwise monological narrative and so

9 on er and also that the texts were not available in electronic form prior to their

10 inclusion to the corpus you say something $<\mathrm{S} 1>[\mathrm{mhm}]</ \mathrm{S} 1>$ [like] but i'm er i'm

11 actually wondering $\mathbf{i}$ don't know if this is er obvious answer to this question but

12 wouldn't it make sense to to apply a more fine-grained internal classification to

13 the texts so that you do get $<\mathrm{S} 1>[\mathrm{mhm}]</ \mathrm{S} 1>$ [into] the corpus that are available

14 in electronic form because you you chose basically one $\mathrm{i}$ think internal parameter

$15<$ S1 $>$ mhm $</$ S $1>$ which was which was year of publication $</$ S3 $>$

Note: Details about the participants' Native Language Status, Academic Role, Gender and Age are S1: Russian; junior staff; male; 31-50; S2: Finnish; senior staff; male; 51-over; S3: Swedish; senior staff; male; $31-50$ 
In excerpt 1 above, $<$ S3> starts with an agreement by okaying a set of explanations in $<$ S1 $>$ 's previous turn and then switches to another topic which he will comment on later towards the end of his turn. The first half of this lengthy turn by $<$ S3 $>$ (see lines between 1 and 10) includes a series of restatements of what S1 has discussed in his dissertation (e.g., ...it's hard to use internal effects to classification parameters... and ...you give basically two reasons that the corpus consists of...). This prolonged elaboration is accompanied by $<\mathrm{S} 1>$ 's frequent backchanneling (e.g., eight times $\mathrm{mhm}$ during the entire turn of $<\mathrm{S} 3>$ ), which signals his involvement as an addressee in this interaction as well as understanding in an agreeing manner. In line 11, following all those restatements from line 1 to $10,<$ S3> uses epistemic stance marker I don't know to position himself as 'not sure' toward his own upcoming comment or suggestion (...but i'm er i'm actually wondering $i$ don't know if this is er obvious answer to this question) on the methodological aspect of <S1>'s dissertation. Even though the use of $I$ don't know by $<\mathrm{S} 3>$ indicates his epistemic positioning on a certainty/uncertainty scale, his utterance in line 11 basically prefaces his suggestion, or probably counterargument, (...but wouldn't it make sense to to apply a more fine-grained internal classification to the texts so that you do get...) on <S1>'s methodology till the end of his monologue-type turn. Through the use of 'actually' in line 10 for the sake of making a transition in discourse (Waters, 2009) to prepare the hearer and the use of $I$ don't know in a clausal position as a verbal routine form (Baumgarten \& House, 2010), <S3> attempts to mitigate and signal his intention to position himself towards his alternative suggestion for a more fine-grained internal classification. Given that the interaction is a part of a dissertation defense discussion and <S3>'s role is basically to be critical in such a speech event, he uses epistemic stance marker I don't know as a face-maintaining strategy to present his methodological perspective and suggest what to do in a rather indirect way. Despite his assigned role as an examiner or opponent in this defense discussion and supposed authority regarding his seniority, knowledge, and experience, <S3>'s preference for indirectness through stancetaking plays an important role in the making of facework or relational work in such interactions in academic settings (Çiftçi \& Vásquez, 2020).

\subsection{Seeking acceptance}

Our dataset also involves another instance of $I$ don't know as a face-maintaining strategy in the case of seeking acceptance by $<\mathrm{S} 2>$ in the excerpt 2 below. The excerpt is a part of a doctoral dissertation defense discussion after the presentation on politics of memory and emotions in Pakistani women's life-writing in the academic discipline of political sciences. A total of 95-minute-interaction involves a male and two female interlocutors who are native speakers of Finnish and Italian. $<$ S2 $>$ is a junior staff defending her dissertation, and $<\mathrm{S} 1>$ and $<$ S3 $>$ are senior staff who ask questions or make comments throughout the discussion. 


\section{Excerpt 2}

$1<$ S3> by the [father yes] $</$ S $3>$

$2<$ S2 $>$ [by the father's] father's death $<$ S3 $>$ mhm-hm $</$ S $3>$ and er this is er er you

3 can call this kind these kinds of pacts feminism but at the same time you have to

4 you can't only read that er there are also other kinds of story lines going on there

$5<$ S3> mhm-hm </S3> and there are other moments where she doesn't constantly

6 she doesn't always refer to her father and there are l-lots of er er in these stories i

7 have actually wanted to show how the women interact with other women and if

8 there are these kinds of women's spaces women's political spaces where erm er

9 there isn't always reference to the men as significant others $<$ S3 $>$ mhm-hm $</ \mathrm{S} 3>$

10 so erm i don't know if $i$ have fully answered your $<\mathrm{S} 3>[\mathrm{mhm}]</ \mathrm{S} 3>$ [question]

11 but you can sort of throw [it back to me] $</ \mathrm{S} 2>$

$12<$ S3> [yes now i] i am simply wondering whether $\mathrm{mhm}$, patriarchy as a category

13 can give us some er hints at understanding er power relations $<$ S2 $>[\mathrm{mhm}]</ \mathrm{S} 2>$

14 [in] that country $<\mathrm{S} 2>[\mathrm{mhm}-\mathrm{hm}]</ \mathrm{S} 2>$ [is it] a valuable category or isn't it a

15 valuable [category] $</$ S $3>$

Note: Details about the participants' Native Language Status, Academic Role, Gender and Age are S1: Finnish; senior staff; male; 51-over; S2: Finnish; junior staff; female; 31-50; S3: Italian; senior staff; female; $31-50$

Initial to the following short segment of defense discussion, $<\mathrm{S} 2>$ explains how she has examined the narratives of three eminent and powerful women characters and their own autobiographic voices, one of whom is Benazir Bhutto from Pakistan. In relation to the earlier question by $<\mathrm{S} 3>$ on the relationship between patriarchy and power relations, $<\mathrm{S} 2>$ elaborates on how she has wanted to show women interaction or women political spaces through Benazir Bhutto's narratives as she does not always refer to the men as significant others. The segment of this relatively longer turn between lines 2-9 is sporadically backchannelled by <S3>'s $m h m$ agreement tokens. Right at the end of her turn, $<$ S2 $>$ uses $I$ don't know as an epistemic stance marker positioning herself uncertain to preface her intention to seek acceptance for what she has just explained (so erm $i$ don't know if $i$ have fully answered your $<S 3>$ [mhm] $</ S 3>$ [question] in line 10). It is important to note that this act of stancetaking seems to be accepted by $<\mathrm{S} 3>$ through his backchanneling as a sign of his uptake. In this instance of I don't know, $<\mathrm{S} 2>$ as the research student indicates not only her uncertainty level for the propositional content of having been able to fulfill the expectation for answering the question posed by $<\mathrm{S} 3>$, the senior staff, but also implies her intention to get approval or acceptance for the account she has provided, which directly contributes to potential facework between a research student and opponent in a doctoral dissertation defense discussion. Such interactional practices of 
achieving mutual understanding and forming common ground in a supportive manner is also evident in ELF communication (Jenkins, Cogo, \& Dewey, 2011; Kaur, 2009).

\subsection{Hedging or mitigating}

Excerpt 3 below is a segment of a doctoral dissertation defense discussion in the academic discipline of information technology. An interaction of 140 minutes 30 seconds takes place among four interlocutors. $\langle\mathrm{S} 1\rangle$, the male research student, is the native speaker of Romanian and other 2 interlocutors, who are senior staff, speak Swedish and Norwegian as their first languages. $<\mathrm{S} 4>$ 's native language is not known. $<\mathrm{S} 1>$ as a research student in technology defends his dissertation on system components for video demand and others as senior staff comment and ask questions throughout the discussion.

\section{Excerpt 3}

$1<$ S3 $>$ so the table on page 73 is the is the actual measured transport delays $</$ S $3>$

$2<$ S1> er, yes but the, the so this is er yeah they are they are actual measured

3 delays $<$ S $3>\mathrm{mhm}</ \mathrm{S} 3>$ but then this is er they are delays of the commands and

4 it's maybe not the delay of the transport stream itself $</ \mathrm{S} 1>$

$5<$ S3> so what would the delay of the transport stream be in in the order and what's

6 the delay of the codec in the order $</$ S3 $>$

$7 \quad<$ S1> er i don't know but i would say that in video conferencing the the codec

8 should be should be er a litt- i'd say litt- little bit different i'm not very familiar

9 with M-PEG-4 but in M-PEG-2 er maybe it's not so good to use (displays) because

10 of the extra delay in ( $\mathrm{xx}$ ) yeah that is $\langle$ S3 $>\mathrm{mhm}</ \mathrm{S} 3>$ so to to have very very

11 short delays between er frame capture on one side then frame display on the other

12 side i think there are several things to (work at), er the the measurements here

13 were done in two computers in the same sub $<\mathrm{S} 3>[\mathrm{mhm}]</ \mathrm{S} 3>[(\mathrm{xx})]$ so the delay

14 between the rounded delay $\mathrm{i}$ think was below one second $</ \mathrm{S} 1>$

Note: Details about the participants' Native Language Status, Academic Role, Gender and Age are S1: Romanian; research student; male; 24-30; S2: Swedish; senior staff; male; 31-50; S3: Norwegian; senior staff; male; 31-50; S4: unknown; senior staff; male; 51-over

Initial to this segment of dissertation discussion above, $<\mathrm{S} 3>$ and $<\mathrm{S} 1>$ are discussing the issue of time delays in M-PEG-4 in a video conferencing setting and S1 gives a possible explanation of why time delays in M-PEG-4 might be different from those in M-PEG-2 regarding video conferencing. Then, the excerpt 3 starts with a move by S3 turning their attention to the table on page 73 to confirm if it is the actual measured transport delays. In lines $2-4,<\mathrm{S} 1>$ provides a confirmation for what is indicated in the mentioned table and this is followed by additional details on the type of delays and possibility of not being the delay of the transport stream itself. Then, 
$<$ S3> confronts this with a question asking what it would be then (e.g., the delay of the transport stream in lines 5-7). Taking the floor in line 7 to answer $<$ S3>'s question, $<\mathrm{S} 1>$, the research student, initiates his turn with a filler er followed by epistemic stance marker $i$ don't know but to preface his potential explanation again for the time delays in video conferencing regarding the codec (see lines 7-14). The act of stancetaking at the beginning of $<\mathrm{S} 1>$ 's turn does not only indicate his positioning of being uncertain towards the topic at hand but also mitigates his proposition functioning as a hedge. Thus, the stance act by $<\mathrm{S} 1>$ at the beginning of his turn starting in line 7 mitigates his answer to the question directed by $<\mathrm{S} 3>$, the senior staff, along with other co-occurring hesitation or uncertainty features (e.g., repetitions, pause filler er, expression of unfamiliarity with I'm not very familiar, uncertainty with er maybe it's not).

\subsection{Checking agreement}

The excerpt 4 is a segment of the same doctoral dissertation defense discussion with the one in the excerpt 2 above, where $<$ S2 $>$ has just given her dissertation presentation on politics of memory and emotions in Pakistani women's life-writing in the field of political sciences.

\section{Excerpt 4}

$1<$ S2> ... i just felt that er er in this particular kristeva's text er when i when $\mathrm{i}$

2 started reading this together with the pakistani women's texts which were full of

3 action $<$ S3 $>$ [mhm] $</ \mathrm{S} 3>$ [and] full of er sort of very personal kind of words this er

4 in this context it started to seem somehow hollow $<$ S3 $>[\mathrm{mhm}]</ \mathrm{S} 3>$ [but] then in

5 other instances if $\mathrm{i}$ if $\mathrm{i}$ read this the text in an other $<\mathrm{S} 3>[\mathrm{mhm}-\mathrm{hm}]</ \mathrm{S} 3>$

6 [context] i er the interpretation will be again different $</ \mathrm{S} 2>$

$7 \quad<$ S3> yes from what you er now just said er i see that the the the role that er some

8 feminist writing plays is perhaps er more important than what is actually showed

9 er and what is actually spoken out so to say $<$ S2 $>$ [mhm-hm] $</ \mathrm{S} 2>$ [in the text] er

10 to my mind er my personal position would be and $\mathbf{i}$ don't know if you agree on

11 this that er perhaps these so-called essentialist feminists $<$ S2 $>$ mhm-hm $</$ S2 $>$ er

12 at some point can be more useful in the at least in the starting encounter with

13 different women $<$ S2 $>$ mhm-hm $</$ S2 $>$ than the post-structuralists so to say or

14 post-modern er feminist discourse which $<$ S2 $>$ [yeah] $</$ S2 $>$ [somehow] hinders

15 from speaking at all with the [other] $</ \mathrm{S} 3>$

$16<$ S2> [yeah] yes because er with with the so-called essentialist theorist you at

17 least have something to hold on to $<$ S3 $>$ yes $</$ S3 $>$ and you have something to

18 argue against you $<$ S3 $>$ [yes] </S3> [have] very strong arguments against which 
19 you can position [yourself] $<$ S3 $>$ [yes] yes $</$ S $3>$ but then with the post-

20 structuralist it er er theorising it's it seems to somehow float..

Note: Details about the participants' Native Language Status, Academic Role, Gender and Age are S1: Finnish; senior staff; male; 51-over; S2: Finnish; junior staff; female; 31-50; S3: Italian; senior staff; female; $31-50$

Prior to $<$ S3>'s turn starting in line $7,<$ S2 $>$ reflects on her experience of reading feminist women writers and then compares this with Pakistani women's texts (lines 1-6). In response to this, $<$ S3 $>$ immediately acknowledges this with a blunt yes and then states her understanding of what $<\mathrm{S} 2>$ has just expressed (from what you er now just said er $i$ see that... in line 7). Following this, <S3> adds her own point of view ( $m y$ personal position would be..) by simultaneously checking <S2>'s agreement (and $i$ don't know if you agree on this..) through an epistemic stance marker I don't know in line 10. This act of checking agreement on an epistemic scale also prefaces <S3>'s propositional content in lines 11-15 regarding the feminist discourse <S1> has brought up in her previous turn. Then, $<$ S2 $>$ takes the turn and elaborates on her comparison of different feminist theorists (see lines 16-20). Overall, each interlocutor shows their involvement or listenership by using frequent backchannelling (e.g., $\mathrm{mhm}$ ) and agreement tokens yeah and yes.

\subsection{Expressing uncertainty}

Excerpt 5 below is a segment of a doctoral dissertation defense discussion in the academic domain of technology. Three interlocutors who are native speakers of Finnish and German are involved in an interaction of 176 minutes 17 seconds. <S1> is a male research student in information technology and defends his dissertation on interconnection architectures for on-chip digital systems. $<$ S2>'s academic role is unknown and $<\mathrm{S} 3>$ is a senior staff member who comments and asks questions throughout the discussion as the opponent.

\section{Excerpt 5}

$1<$ S3> and, er can you give a formula how the leakage power depends on something

2 (or the) and you (looked as) a sup- special current that is flowing in the

3 transistors $</ \mathrm{S} 3>$

$4<$ S1 $>$ it's just the (if you if you have) the current it's current times the er

5 voltage $</ \mathrm{S} 1>$

$6<$ S3> i didn't understand that $</$ S3 $>$

$7<$ S1> well i i'm not sure i don't know what what formula are you aiming at here

8 usually it's just the if you have some sort of leakage current then the (it's) current

9 current times the voltage $</ \mathrm{S} 1>$

Note: Details about the participants' Native Language Status, Academic Role, Gender and Age are S1: Finnish; research student; male; 31-50; S2: Finnish; unknown role; male; 31-50; S3: German; senior staff; male; 51-over 
Right before the segment of doctoral dissertation defense above, $<$ S1 $>$ and $<$ S3 $>$ discuss how $<$ S1 $>$ handled physical interconnection and types of power dissipation in his dissertation. More specifically, $<\mathrm{S} 1>$ explains dynamic power dissipation, short circuit, and then how leakage power is obtained as it is asked by $<\mathrm{S} 3>$ to see how he understands these concepts. Following this, the excerpt 5 above starts with even a more specific question by $<\mathrm{S} 3>$ as he asks can you give a formula how the leakage power depends on something. The answer by $<\mathrm{S} 1>$ to this question is, however, not understood by the $<$ S3 $>$ as can be seen in line 6 . At this point, we see how $<$ S $1>$, the research student, reacts to this by using $I$ don't know as an epistemic stance marker to express his uncertainty and show his own non-understanding of what formula $<\mathrm{S} 3>$ is actually expecting (in lines 7-9).

\section{Discussion}

In our analysis, drawing on a discourse analytic perspective, we examined stancetaking through $I$ don't know in its own context by paying attention to actual instantiations of ELF interactions in natural academic settings. In doing so, we argue that the use of epistemic stance marker I don't know under scrutiny in our analysis serves interpersonal goals of the participants in ELF communication revealing five primary functions as a face-maintaining strategy: prefacing a suggestion, seeking acceptance, hedging an explanation, checking agreement, and expressing uncertainty. Thus, unlike previous research on stance in native speaker interactions or corpus in English (Biber, Conrad, \& Leech, 2002; Kärkkäinen, 2007; Precht, 2003; Scheibman, 2007), our study contributes to the understanding of stance in ELF discourse in academic settings (Çiftçi \& Vásquez, 2020).

From an interpersonal perspective, our study demonstrates that stancetaking through I don't know is intersubjectively employed by the participants at points in academic discourse to achieve their interpersonal goals in the form of a facemaintaining strategy. As we have seen in the extracts, the participants essentially construct different interactional and pragmatic meanings other than simply denoting their insufficient knowledge towards propositions through their stancetaking acts. For example, the verbal routine form Excerpt 1 provides a case for preparing the hearer for a modestly-uttered suggestion out of many while letting the speaker position himself by maintaining his face as the suggestion-provider. As a means of supplying speaker's mitigation, as in Excerpt 3, I don't know could also be uttered to function as prefacing uncertainty with respect to what is conveyed. With the help of involvement expressions (i.e., $m h m, m h m-h m$ ) as backchanneling by the co-participants occurring very close to the instances of $I$ don't know as in Excerpts 2, 3 and 4, we believe that the stancetaking through this particular expression becomes more dialogically negotiated in academic discourse in which co-participants jointly construct and reflect their intersubjectivity, and simultaneously contribute to the facework among themselves.

It is also noteworthy to highlight that our understanding of stancetaking from a sociolinguistic (Jaffe, 2009) and interpersonal perspective (Locher \& Graham, 2010; O'Driscoll, 2013) has enabled us to understand this communicative act in its own 
socially situated context where interlocutors bring their own understanding of social norms and negotiated practices in discourse. That is, the function of stancetaking in discourse can show variation depending on the speech event at hand, topic, sociolinguistic background of the participants and their interpersonal goals in discourse. In that sense, considering the act of stancetaking in ELF discourse in academic settings, we have situated our analysis within the actual ELF communication taking place, linguistic, interactional, and sociolinguistic features of these actual interactions. We thus argue that functions of stancetaking in ELF discourse are negotiated by the participants during the interaction and how these functions contribute to the relational and interpersonal aspect of communication depends on such negotiations as ELF users work for a co-constructed mutual understanding (Jenkins et al., 2011) and thus primarily focus on the goal or function of their talk and on the participants in discourse (Seidlhofer, 2009). We believe that our study attempts to make a contribution to research in this strand by uncovering the interpersonal functions of stancetaking in ELF discourse.

\section{Conclusion}

We have examined how I don't know as an epistemic stance marker is used in doctoral dissertation defense discussions as one type of speech events in ELF academic discourse. Rather than exploring the linguistic construction of stance in such interactions, we have aimed to understand stancetaking at an epistemic scale mainly as an act of evaluation and positioning by the participants (Du Bois, 2000) where they index their own subjectivity towards an argument, a propositional content, and/or a suggestive verbal act. Our study is limited to a specific context of ELF academic discourse and 14 doctoral dissertation defense discussions. As we embrace the premise that meaning is socially situated within its context, more discourse analysis studies on different pragmatic aspects of language could be helpful to understand how language is used in ELF interactions. The act of stancetaking might also be examined in other speech events other than doctoral dissertation defense discussions. Last but not least, we also believe that a multimodal analysis of such interactions could focus on the analysis of embodied actions, which requires a more detailed transcription combining verbal and non-verbal resources (Girgin et al., 2020).

\section{The Research and Publication Ethics Statement}

As the ELFA corpus is freely and publicly available to researchers, this did not require us to go through any processes of the Ethics Committee/Board approval. For more information, please see the ELFA corpus website:

https://www.helsinki.fi/en/researchgroups/english-as-a-lingua-franca-in-academicsettings/research/elfa-corpus 


\section{The Conflict of Interest Statement}

In line with the statement of Committee on Publication Ethics (COPE), we hereby declare that we had no conflicting interests regarding any parties of this study.

\section{References}

Anthony, L. (2019). AntConc (3.5.8) [Computer Software]. Tokyo, Japan: Waseda University. Available from http://www.antlab.sci.waseda.ac.jp/

Arundale, R. B. (2013). Conceptualizing ‘interaction' in interpersonal pragmatics: Implications for understanding and research. Journal of Pragmatics, 58, 12-26. http://dx.doi.org/10.1016/j.pragma.2013.02.009

Baird, R., Baker, W., \& Kitazawa, M. (2014). The complexity of ELF. Journal of English as a Lingua Franca 3(1), 171-196, doi: https://doi.org/10.1515/jelf-2014-0007

Bakhtin, M. M. (1981). The dialogic imagination: Four essays. Austin, TX: University of Texas Press.

Baumgarten, N., \& House, J. (2010). I think and I don't know in English as lingua franca and native English discourse. Journal of Pragmatics 42, 1184-200. https://doi.org/10.1016/j.pragma.2009.09.018

Biber, D. (2004). Historical patterns for the grammatical marking of stance. A cross-register comparison. Journal of Historical Pragmatics 5(1), 107-136. https://doi.org/10.1075/jhp.5.1.06bib

Biber, D., Conrad, S., \& Leech, L. (2002). Longman student grammar of spoken and written English. Essex: Pearson.

Biber, D., \& Finegan, E. (1988). Adverbial stance types in English. Discourse Processes 11, 134. http://dx.doi.org/10.1080/01638538809544689

Biber, D., \& Finegan, E. (1989). Styles of stance in English: Lexical and grammatical marking of evidentiality and affect, Text 9(1), 93-124. https://doi.org/10.1515/text.1.1989.9.1.93

Conrad, S., \& Biber, D. (2000). Adverbial marking of stance in speech and writing. In S. Hunston \& G. Thompson (Eds.), Evaluation in Text: Authorial Stance and the Construction of Discourse (56-73). New York: Oxford University Press.

de Abreu, G. (2000). Relationships between macro and micro socio-cultural contexts: implications for the study of interactions in the mathematics classroom. Educational Studies in Mathematics 41, 1-29. https://doi.org/10.1023/A:1003875728720

Çiftçi, H., \& Vásquez, C. (2020). Co-constructed oppositional stance and facework in an office hour interaction. Journal of Politeness Research, 16(2), 193-216. https://doi.org/10.1515/pr$\underline{2017-0013}$

Drew, P., \& Heritage, J. (1992). Analyzing talk at work: an introduction. In P. Drew \& J. Heritage (Eds.), Talk at work: Interaction in institutional settings (3-65). Cambridge: Cambridge University Press.

Du Bois, J. (2000). Taking a stance: Constituting the stance differential in dialogic interaction. Paper presented at the Annual Meeting of the American Anthropological Association, San Francisco, November 18.

Du Bois, J. W. (2007). The stance triangle. In R. Englebretson (Ed.), Stancetaking in Discourse: Subjectivity, Evaluation, Interaction (139-182). Pennsylvania: John Benjamins.

ELFA. (2008). The Corpus of English as a Lingua Franca in Academic Settings. Director: Anna Mauranen. http://www.helsinki.fi/elfa (June 30, 2020).

Englebretson, R. (2007). Stancetaking in discourse: Subjectivity, evaluation, interaction. 
Amsterdam: John Benjamins Publishing Company.

Gee, J. P. (2011). An introduction to discourse analysis: Theory and method. New York:

Routledge.

Girgin, U., Acar, Y., Akbaş, E., Yavuz, E., Altan, A. E., Boran, M., ... Moralı, G. (2020). Conversation Analysis Methodology: Validity, Reliability, and Ethical Issues in Data Collection and Analysis Procedures. Hacettepe University Journal of Education. Advance online publication. https://doi.org/10.16986/HUJE.2020063458

Goffman, E. (1967). Interaction Ritual: Essays on Face-to-Face Behavior. Garden City, NY: Anchor Books.

Haddington, P. (2005). The intersubjectivity of stance taking in talk-in-interaction. Unpublished Ph.D. dissertation, English Department, University of Oulu.

Haddington, P. (2007). Positioning and alignment as activities of stancetaking in news interviews. In R. Englebretson (Ed.) Stancetaking in Discourse: Subjectivity, Evaluation, Interaction (283- 317). Pennsylvania: John Benjamins.

House, J. (2013). Developing pragmatic competence in English as a lingua franca: Using discourse markers to express (inter)subjectivity and connectivity. Journal of Pragmatics, 59, 57-67. https://doi.org/10.1016/j.pragma.2013.03.001

Hunston, S. (2007). Using a corpus to investigate stance quantitatively and qualitatively. In R. Englebretson (Ed.), Stancetaking in Discourse: Subjectivity, Evaluation, Interaction (2748). Pennsylvania: John Benjamins.

Hunston, S., \& Thompson, G. (2000). Evaluation in text: Authorial stance and the construction of discourse. Oxford: Oxford University Press.

Hülmbauer, C. (2009). We don't take the right way. We just take the way that we think you will understand: The shifting relationship of correctness and effectiveness in ELF communication. In A. Mauranen \& E. Ranta (Eds.), English as a Lingua Franca: Studies and findings (323-347). Newcastle upon Tyne: Cambridge Scholars.

Jaffe, A. (2009). Introduction: The sociolinguistics of stance. In A. Jaffe (Ed.), Stance: Sociolinguistic perspectives ed. (3-28). New York, NY: Oxford University Press.

Jenkins, J., Cogo, A., \& Dewey, M. (2011). Review of developments in research into English as a lingua franca. Language Teaching, 44(3), 281-315. https://doi.org/10.1017/S0261444811000115

Kaur, J. (2009). Pre-empting problems of understanding in English as lingua franca. In A. Mauranen, and E. Ranta (Eds.), English as a Lingua Franca: Studies and findings (107123). Newcastle upon Tyne: Cambridge Scholars.

Kärkkäinen, E. (2006). Stance taking in conversation: From subjectivity to intersubjectivity. Text \& Talk, 26(6), 699-731. https://doi.org/10.1515/TEXT.2006.029

Kärkkäinen, E. (2007). The role of I guess in conversational stancetaking. In R. Englebretson (Ed.), Stancetaking in Discourse: Subjectivity, Evaluation, Interaction (183-220). Pennsylvania: John Benjamins.

Li, J., Lei, L., \& Cheng, L. (2020). Mapping evaluation, appraisal and stance in discourse (2000-2015): A bibliometric analysis. Glottotheory, 10(1-2), 31-55. https://doi.org/10.1515/glot-2019-0002

Locher, M. A., \& Graham, S. L. (2010). Introduction to interpersonal pragmatics. In M. A. Locher \& S. L. Graham (Eds.), Interpersonal Pragmatics (1-13). Berlin: Mouton.

Locher, M. A., \& Watts, R. J. (2005). Politeness theory and relational work. Journal of Politeness Research, 1(1), 9-33. https://doi.org/10.1515/jplr.2005.1.1.9 
Martin, J. (2000). Beyond exchange: appraisal systems in English. In S. Hunston \& G. Thompson (Eds.), Evaluation in Text: Authorial Stance and the Construction of Discourse (142-175). New York: Oxford University Press.

Mauranen, A. (2006). A rich domain of ELF - the ELFA corpus of academic discourse. Nordic Journal of English Studies, 5(2), 145-59. https://doi.org/10.35360/njes.15

Mauranen, A. (2018). Conceptualising ELF. In J. Jenkins, W. Baker \& M. Dewey (Eds.), The Routledge handbook of English as a lingua franca (7-24). Oxon: Routledge.

Metsä-Ketelä, M. (2006). Words are more or less superfluous: The case of more or less in academic lingua franca English. Nordic Journal of English Studies, 5(2), 117-143. https://doi.org/10.35360/njes.14

O'Driscoll, J. (2013). The role of language in interpersonal pragmatics. Journal of Pragmatics, 58, 170-181. https://doi.org/10.1016/j.pragma.2013.09.008

Precht, K. (2003). Stance moods in spoken English: Evidentiality and affect in British and American conversation. Text, 23, 239-257. https://doi.org/10.1515/text.2003.010

Scheibman, J. (2007). Subjective and intersubjective uses of generalizations in English conversations. In R. Englebretson (Ed.), Stancetaking in Discourse: Subjectivity, Evaluation, Interaction (111-138). Pennsylvania: John Benjamins.

Seidlhofer, B. (2009). Common ground and different realities: world Englishes and English as a lingua franca. World Englishes, 28(2), 236-245. https://doi.org/10.1111/j.1467971X.2009.01592.x

Silver, M. (2003). The stance of stance: A critical look at ways stance is expressed and modeled in academic discourse. Journal of English for Academic Purposes, 2(4), 359-374. https://doi.org/10.1016/S1475-1585(03)00051-1

Swales, J. (1990). Genre analysis: English in academic and research settings. Cambridge: Cambridge University Press.

Thompson, G., \& Hunston, S. (2000). Evaluation: An introduction. In S. Hunston \& G. Thompson (Eds.), Evaluation in Text: Authorial Stance and the Construction of Discourse (1-27). New York: Oxford University Press.

Vickers, C. H., Deckert, S. K., \& Goble, R. (2014). Constructing language normativity through the animation of stance. Health Communication, 29(7), 707-716. https://doi.org/10.1080/10410236.2013.778224

Waters, C. (2009). Actually, it's More Than Pragmatics, it's Really Grammaticalization". Toronto Working Papers in Linguistics, June. https://twpl.library.utoronto.ca/index.php/twpl/article/view/6537.

\section{Copyrights}

Copyright for this article is retained by the author(s), with first publication rights granted to the Journal.

This is an open-access article distributed under the terms and conditions of the Creative Commons Attribution license (CC BY-NC-ND) (http://creativecommons.org/licenses/by-nc-nd/4.0/) 